\title{
METODOLOGIAS FEMINISTAS E ESTUDOS DE GÊNERO: ARTICULANDO PESQUISA, CLÍNICA E POLÍTICA
}

Martha Giudice Narvaz*

Sílvia Helena Koller

\begin{abstract}
RESUMO. Este texto busca dar visibilidade ao feminismo enquanto projeto teórico-epistemológico e político e suas possíveis articulações com a pesquisa acadêmica e com a clínica feminista. Inicialmente, situamos o conceito de feminismo como movimento histórico, político e filosófico-epistemológico; apresentamos as gerações, comumente conhecidas como ondas do feminismo, apontando algumas de suas principais características e problematizações. Posteriormente, desenvolvemos considerações sobre as diferentes epistemologias, metodologias e terapias feministas. Ao final, destacamos que a falta de institucionalização dos estudos feministas e de gênero enquanto saberes legítimos e integrados aos currículos universitários revela a posição marginal que tais estudos ainda ocupam na Academia, na Pesquisa e na Clínica.
\end{abstract}

Palavras-chave: feminismo, metodologias feministas, gênero.

\section{FEMINIST METHODOLOGIES AND GENDER STUDIES: ARTICULATING RESEARCH, THERAPY AND POLITICS}

\begin{abstract}
This article presents feminism as a theoretical, epistemological and political project, as well as its articulations between the academic research and the feminist therapy. Initially, the feminist concept is emphasized as a historical, political and philosophical-epistemological movement. The feminism generations, commonly known as waves of the feminism, are shown, pointing out their main characteristics and concerns. In addition, considerations about different feminist epistemologies, methodologies and therapy are developed. Finally, the lack of institutionalization of studies on feminist and gender, as a legitimate knowledge incorporated to the academic curriculum is highlighted, thus revealing the marginal position that such studies still currently occupy in the Academic, Research and Therapeutic Fields.
\end{abstract}

Key words: Feminism, feminist methodology, gender.

\section{METODOLOGÍAS FEMINISTAS Y ESTUDIOS DE GÉNERO: ARTICULANDO PESQUISA, CLÍNICA Y POLÍTICA}

RESUMEN. Este texto busca dar visibilidad al feminismo mientras proyecto teórico-epistemológico y político y sus posibles articulaciones con la investigación académica y con la clínica feminista. Inicialmente, situamos el concepto de feminismo como movimiento histórico, político y filosófico-epistemológico; presentamos las generaciones, comúnmente conocidas como olas del feminismo, apuntando algunas de sus principales características y problematizaciones. Posteriormente, desarrollamos consideraciones sobre las diferentes epistemologías, metodologías y terapias feministas. Al final, destacamos que la falta de institucionalización de los estudios feministas y de género mientras saberes legítimos e integrados a los currículos universitarios revela la posición marginal que tales estudios aún ocupan en la Academia, en la Pesquisa y en la Clínica.

Palabras-clave: feminismo, metodologías feministas, género.

* Psicóloga e Terapeuta Familiar. Doutoranda em Psicologia do Desenvolvimento pela Universidade Federal do Rio Grande do Sul.

\# Psicóloga, Professora do Programa de Pós-Graduação em Psicologia do Desenvolvimento da Universidade Federal do Rio Grande do Sul. 
As teorias, antes que verdades absolutas, são apenas diferentes maneiras de construir e organizar o conhecimento e referendar uma práxis legitimada por determinada comunidade científica em determinado contexto histórico. A pós-modernidade trouxe-nos a pluralidade e o questionamento das certezas como marcas de uma época em que não há um único modelo a ser seguido (Bombassaro, 1995; Chalmers, 1993; Gergen, 1985). Diferentes paradigmas de pesquisa, qualitativos e quantitativos, coexistem na atualidade como formas igualmente válidas de construção do conhecimento científico. A escolha destes paradigmas deve ser adequada aos problemas que se propõem a investigar e aos interesses e filiações teóricas de cada pesquisador (Benz \& Newman, 1998; Habermas, 1982). As formas pelas quais problematizamos uma questão afetam o modo como a investigamos, tanto quanto diferentes métodos de investigação destacam diferentes evidências e, assim, podem conduzir a diferentes resultados (Slife \& Williams, 1995; Wilkinson, 1986).

Não é mais possível, destarte, dissociar teoria e método, tampouco negligenciar os aspectos epistemológicos, ideológicos e éticos envolvidos na escolha de um paradigma de pesquisa. Torna-se cada vez mais importante conhecer os implícitos do paradigma eleito, uma vez que este tem importantes implicações práticas na condução da investigação. Faz-se necessário, nesse sentido - embora isso ainda sejam um tabu em nosso meio científico - assumir que tais escolhas são um ato político, mesmo em se tratando de escolhas de métodos de pesquisa e de teorias que fundamentam o empreendimento de pesquisa (Fonseca, 1997; Neves \& Nogueira, 2005).

Entendendo que toda atividade humana, na medida em que está implicada, é política, é preciso que explicitemos nossos pressupostos teóricoepistemológicos e, ao fazê-lo, assumamos os aspectos político-ideológicos inerentes às nossas práticas. Quer na pesquisa, quer na academia ou na clínica, estes aspectos têm sido comumente negligenciados ou mesmo recusados, sob a também ideológica pretensão de neutralidade e objetividade. Tal recusa pode ser compreendida como uma estratégia das elites brancas masculinas e burguesas (que geralmente detêm a hegemonia dos espaços de poder-saber), ao tentarem evitar a responsabilidade sobre as motivações e sobre as conseqüências dos saberes produzidos, o que não só as feministas, mas também movimentos pacifistas, antiracistas e antiimperialistas, entre outros, têm ousado, há muito, questionar e denunciar (Harding, 1991).
Com base nessas considerações é que buscamos, neste trabalho, dar visibilidade à contribuição das teorias e das práticas feministas que remetem - não só na militância, mas também na clínica, na academia e na pesquisa - ao caráter ativista intrínseco à ética das abordagens críticas (Guba \& Lincoln, 1994). Outros modos de se pensar e se fazer teoria, pesquisa e terapia são encontrados nas epistemologias, nas metodologias (Eichler, 1988; Harding, 1986, 1987, 1991; Keller, 1985, 1996; Neves \& Nogueira, 2005; Wilkinson, 1986, 1998) e nas terapias feministas (Goldner, 1985, 1988; Goodrich, Rampage, Ellman \& Halstead, 1990; Hare-Mustin, 1987; Neves \& Nogueira, 2003; Perelberg, 1994; Ravazzola, 1997, 1999; Urry, 1994). Eles estão inscritos em nosso fazer cotidiano enquanto militantes de movimentos sociais, professoras, pesquisadoras e terapeutas comprometidas com a "construção de lugares outros, não centralizados, de saber e poder" (Schmidt, 2004, p. 21), e os compartilhamos com leitores e leitoras através do presente trabalho.

\section{ENTENDENDO O FEMINISMO}

O movimento feminista contemporâneo, reflexo das transformações do feminismo original predominantemente intelectual, branco e de classe média - configura-se como um discurso múltiplo e de variadas tendências, embora com bases comuns. As feministas destacam que a opressão de gênero, de etnia e de classe social perpassa as mais variadas sociedades ao longo dos tempos. Esta forma de opressão sustenta práticas discriminatórias, tais como o racismo, o classismo, a exclusão de grupos de homossexuais e de outros grupos minoritários (Negrão, 2002; Prá, 1997; Toledo, 2003). O feminismo é uma filosofia que reconhece que homens e mulheres têm experiências diferentes e reivindica que pessoas diferentes sejam tratadas não como iguais, mas como equivalentes (Fraisse, 1995; Jones, 1994; Louro, 1999; Scott, 1986). As feministas denunciam que a experiência masculina tem sido privilegiada ao longo da história, enquanto a feminina, negligenciada e desvalorizada. Elas demonstraram, ainda, que o poder foi - e ainda é predominantemente masculino, e seu objetivo original foi a dominação das mulheres, especialmente de seus corpos (Butler, 2003; Millet, 1970; Pateman, 1993).

Segundo Costa e Schmidt (2004, p. 10), "no bojo do projeto do feminismo (histórica e conjunturalmente forjado a partir das lutas sociais) está o entrelaçamento entre teoria e prática política". O feminismo é, portanto, um campo político (Scott, 1986; Toledo, 
2003), tanto quanto teórico-epistemológico (Eichler, 1988; Harding, 1986, 1987; Keller, 1985, 1996; Wilkinson, 1986, 1998), embora tenha assumido variadas tendências. Considerado 'problemático, instável e tenso' (Butler, 2003; Harding, 1986, 1993; Negrão, 2002), o feminismo vem problematizando a si mesmo ao longo dos tempos, desde as doutrinas do feminismo original, em permanente (des)construção. As intersecções do feminismo com os movimentos de luta de classes configuram diferentes movimentos feministas, entre eles: o radical (inclui-se aqui o movimento de mulheres negras), o liberal, o socialista, o marxista e o anarquista (Chrisler \& Smith, 2004; Toledo, 2003). No campo teórico-epistemológico encontramos o empirismo feminista, o ponto de vista feminista e o pós-modernismo ou pós-estruturalismo feminista, corrente contemporânea do feminismo na qual se inscrevem os estudos de gênero (Butler, 2003; Harding, 1987; Louro, 1999). Houve, também, várias gerações ou várias fases no feminismo, conhecidas como "ondas do feminismo" (Costa, 2002; Nogueira, 2001). Essas diferentes fases ocorreram em épocas distintas, historicamente construídas conforme as necessidades políticas, o contexto material e social e as possibilidades pré-discursivas de cada tempo (Scott, 1986). Não há, na atualidade, um só feminismo, unívoco e totalizante, mas vários feminismos (Negrão, 2002).

A primeira geração (ou primeira onda do feminismo) representa o surgimento do movimento feminista, que nasceu como movimento liberal de luta das mulheres pela igualdade de direitos civis, políticos e educativos, direitos que eram reservados apenas aos homens. $\mathrm{O}$ movimento sufragista (que se estruturou na Inglaterra, na França, nos Estados Unidos e na Espanha) teve fundamental importância nessa fase de surgimento do feminismo. O objetivo do movimento feminista, nessa época, era a luta contra a discriminação das mulheres e pela garantia de direitos, inclusive do direito ao voto. Inscreve-se nesta primeira fase a denúncia da opressão à mulher imposta pelo patriarcado.

A segunda fase do feminismo (segunda geração ou segunda onda) ressurge nas décadas de 1960 e 1970, em especial nos Estados Unidos e na França. As feministas americanas enfatizavam a denúncia da opressão masculina e a busca da igualdade, enquanto as francesas postulavam a necessidade de serem valorizadas as diferenças entre homens e mulheres, dando visibilidade, principalmente, à especificidade da experiência feminina, geralmente negligenciada. As propostas feministas que caracterizam determinadas posições, por enfatizarem a igualdade, são conhecidas como "o feminismo da igualdade", enquanto as que destacam as diferenças e a alteridade são conhecidas como "o feminismo da diferença". Para Scott (2005), a questão da igualdade e da diferença deve ser concebida em termos de paradoxo, ou seja, em termos de uma proposição que não pode ser resolvida, mas apenas negociada, pois é verdadeira e falsa ao mesmo tempo. Fraisse (1995) entende que à questão filosóficoepistemológica da igualdade-diferença sobrepõe-se a questão política, sugerindo que diferentes subjetividades, masculinas e femininas, mesmo não sendo idênticas, podem ser iguais, no sentido de serem equivalentes. Introduz-se, assim, a noção de eqüidade e paridade no debate igualdade-diferença dentro dos movimentos feministas.

Nos anos 1980, a crítica pós-modernista da ciência ocidental introduz o paradigma da incerteza no campo do conhecimento. As feministas francesas, influenciadas pelo pensamento pós-estruturalista que predominava na França, especialmente pelo pensamento de Michel Foucault e de Jacques Derrida (ver Pereira, 2004), passam a enfatizar a questão da diferença, da subjetividade e da singularidade das experiências, concebendo que as subjetividades são construídas pelos discursos, em um campo que é sempre dialógico e intersubjetivo. Surge, assim, a terceira fase do feminismo (terceira geração ou terceira onda), cuja proposta concentra-se na análise das diferenças, da alteridade, da diversidade e da produção discursiva da subjetividade. Com isso, desloca-se o campo do estudo sobre as mulheres e sobre os sexos para o estudo das relações de gênero. Neste sentido é que algumas posições, ainda que heterogêneas, distinguem os Estudos Feministas - cujo foco se dá principalmente em relação ao estudo das e pelas mulheres, mantidas as estreitas relações entre teoria e política-militância feminista - dos Estudos de Gênero, cujos pressupostos abarcam a compreensão do gênero enquanto categoria sempre relacional (Scott, 1896). O desafio nesta fase do feminismo é pensar, simultaneamente, a igualdade e a diferença na constituição das subjetividades masculina e feminina. Nesta terceira fase do movimento feminista, observa-se intensamente a intersecção entre o movimento político de luta das mulheres e a academia, quando começam a ser criados nas universidades, inclusive em algumas universidades brasileiras, centros de estudos sobre a mulher, estudos de gênero e feminismos (Louro, 1995; Machado, 1992; Scott, 1986; Toscano \& Goldenberg, 1992).

As três gerações do feminismo, quer em seus aspectos políticos quer nos teórico-epistemológicos, não podem ser entendidas desde uma perspectiva 
histórica linear. As diferentes propostas características de cada uma das fases do feminismo sempre coexistiram, e ainda coexistem, na contemporaneidade. A fase surgida mais recentemente, a terceira geração do feminismo, tem grande influência sobre os estudos de gênero contemporâneos (Louro, 1999). As questões introduzidas pela terceira geração do feminismo revisaram algumas categorias de análise que, apesar de instáveis, são consideradas fundamentais (Harding, 1993; Louro, 1995; Scott, 1986) para os estudos de gênero. Estas categorias estão articuladas entre si, e são: o conceito de gênero; a política identitária das mulheres; o conceito de patriarcado e as formas da produção do conhecimento científico.

\section{Desconstruindo gênero}

As feministas desta última geração problematizaram as teorias essencialistas ou totalizantes das categorias fixas e estáveis do gênero presentes nas gerações anteriores, nas quais "gênero" era definido a partir do sexo enquanto categoria natural, binária e hierárquica, como se existisse uma essência naturalmente masculina ou feminina inscrita na subjetividade. A expressão "totalizante" foi usada para descrever a idéia até então vigente de que havia uma essência, uma única forma estável e homogênea de ser mulher ou de ser homem. Enquanto "sexo" descrevia os aspectos biológicos, "gênero" compreendia a construção cultural que ocorria sobre as diferenças entre homens e mulheres, com base nas diferenças biológicas. Esta concepção foi chamada "sistema sexo-gênero" (ver Pereira, 2004). Na terceira geração, as feministas refutaram tais proposições, desnaturalizando e desconstruindo a perspectiva de gênero das gerações anteriores. $\mathrm{O}$ gênero passou a ser uma categoria relacional e política (Scott, 1986). Não mais baseado nas diferenças biológicas ou "naturais", diz-se que o gênero foi (des)naturalizado. Revisada a idéia binária de dois sexos e dois gêneros, o gênero passou a ser entendido como relação, primordialmente política, que ocorre num campo discursivo e histórico de relações de poder (Scott, 1986). Incorporando as tendências pós-estruturalistas e desconstrucionistas, Butler (2003) conceitua gênero como um 'ato performático', como um efeito, produzido ou gerado. Essa definição resgata a noção de processo e de construção singular de cada sujeito, dentro de um campo situado de possibilidades que é reafirmado ou renegociado através de sucessivas "performances", ou seja, atos, práticas concretas (e não essências naturalizadas) através dos quais os sujeitos se constituem. Gênero é, portanto, uma construção social, uma invenção (Nogueira, 2001).

\section{DESCONSTRUINDO A CATEGORIA "MULHERES"}

Estas novas concepções sobre gênero deram margem ao abandono das teorias essencialistas do sujeito, que definem, entre outras, a categoria "mulheres". Não mais havendo sexo natural nem uma única forma de ser mulher (ou de ser homem), as políticas de identidade do feminismo original, presentes nas gerações anteriores, foram questionadas. Para Butler (2003, p. 213), "Mulheres é um falso e unívoco substantivo que disfarça e restringe uma experiência de gênero variada e contraditória. A unidade da categoria 'mulheres' não é nem pressuposta nem desejada, uma vez que fixa e restringe os próprios sujeitos que liberta e espera representar". Desconstruir o sujeito do feminismo, segundo Costa (2002, p.71), "significa apenas que 'mulher' é uma categoria histórica e heterogeneamente construída dentro de uma ampla gama de práticas e discursos, e sobre os quais o movimento de mulheres se fundamenta." Há que distinguir aqui as "políticas de identidade", que pressupõem a existência de unidade, das "políticas de coalizões", formadas a partir de alianças contingentes (ver Mariano, 2005). Coexistem, assim, correntes feministas que problematizam as políticas identitárias e, com isso, a categoria "mulheres" (Butler, 2003), com teorias que entendem ser possível e necessária a manutenção da unidade da categoria, uma vez concebida tal unidade como resultado de uma fixação parcial de identidades mediante a criação de pontos comuns, ou seja, das lutas políticas que devem ser travadas pelas "mulheres", os "sujeitos do feminismo" (Costa, 2002; Mariano, 2005; Negrão, 2002).

\section{Repensando o patriarcado}

A terceira questão problemática do feminismo é o patriarcado (ver Colling, 2004). Ao patriarcado foi atribuída a gênese da opressão de gênero e, daí, a violência contra as mulheres (Millet, 1970). O capitalismo foi articulado ao patriarcado (Saffioti, 1979, 1988, 2001) na questão da dominação feminina. Algumas correntes marxistas (Toledo, 2003) propõem que o capitalismo é preponderante na questão das desigualdades, embora não desconsiderem a influência do patriarcado na gênese da opressão feminina. Também as terapias feministas (Burck \& Daniel, 1994; Goldner, 1985, 1988; Hare-Mustin, 1987; 
McConaghy \& Cottone, 1988) atribuem à dominação masculina a gênese das desigualdades de gênero, em especial na dinâmica das relações violentas. Contudo, a questão do patriarcado permanece tensa e é campo de debate. Algumas teóricas (Pateman, 1993; Machado, 2000; Saffioti, 1988) advogam existir uma forma de "patriarcado moderno", enquanto outras (Aguiar, 1997; Castro \& Lavinas, 1992) postulam não ser adequado o uso do termo "patriarcado" na modernidade. Para estas últimas, não há uma teoria universalizante do patriarcado. O termo "patriarcado", cunhado por Max Weber (ver Aguiar, 1997), definia sistemas sociais e familiares baseados no reconhecimento da autoridade pela tradição, não podendo ser aplicado às formações sociais que encontramos na atualidade.

\section{AS EPISTEMOLOGIAS E METODOLOGIAS FEMINISTAS}

A epistemologia feminista também não é um domínio estável; ao contrário, representa um espaço de contestação e de dúvida acerca do que é considerado "conhecimento", quem o define e como este é capturado pelo sujeito do conhecimento (Harding, 1986). Mais apropriado seria falar em epistemologias e em metodologias, no plural, uma vez que não há uma só forma de produção do conhecimento, mas várias, a partir de diferentes teorias. As epistemologias feministas abrem-se para um campo multidisciplinar e defendem a pluralidade metodológica. A ciência, na perspectiva das epistemologias feministas, tem gênero, havendo diferentes maneiras de produzir conhecimento. Homens e mulheres fazem ciência de formas diferenciadas. A ciência positivista, considerada androcêntrica pelas epistemologias feministas, associou a objetividade à masculinidade, o que conduziu a presumir que, para ser objetivo, requer-se um distanciamento e uma separação entre razão e emoção (Eichler, 1988; Jaggar, 1997). As epistemologias feministas entendem que o conhecimento é sempre situado, posicionando-se contra a objetividade e a neutralidade características da ciência positivista androcêntrica (Keller, 1985; Harding, 1986) e resgatando o papel da emoção e da experiência feminina na produção do conhecimento científico. A imparcialidade, nesse contexto, não é possível, nem sequer desejável, especialmente porque se encontra comprometida com a mudança social (McHugh \& Cosgrove, 2004; Neves \& Nogueira, 2003; Wilkinson, 1986, 1998). As principais linhas epistemológicas feministas são: o empiricismo feminista, a teoria do ponto de vista feminista (feminist standpoint theory), o construcionista social, o feminismo pós-moderno (pósestruturalista e desconstrucionista) e, mais recentemente, a epistemologia feminista com base na física quântica e a pesquisa irônica (satirical empiricism) (Harding, 1986, 1987; McHugh \& Cosgrove, 2004).

As metodologias feministas são descritas na literatura (Bruschini, 1992; Chrisler \& Smith, 2004; Dias, 1992; McHugh \& Cosgrove, 2004; Neves \& Nogueira, 2003) como instrumentos ou estratégias de mudança social que refletem perspectivas de diferentes epistemologias. A complexidade da investigação feminista envolve a preocupação com todo o processo de condução da investigação. As preocupações comuns das diversas epistemologias e metodologias iniciam com a escolha do delineamento a ser utilizado na pesquisa, uma vez que diferentes métodos conduzem a diferentes resultados. Os pressupostos epistemológicos, ontológicos e éticos implícitos nos delineamentos de pesquisa têm implicações políticas, podendo estar a serviço de interesses diversos. As metodologias feministas assumem o caráter intrínseco das abordagens críticas (Guba \& Lincoln, 1994), tendo como objetivo comum a mudança social, o resgate da experiência feminina, o uso de análises e de linguagens não sexistas (Eichler, 1988) e o empoderamento dos grupos oprimidos, em especial das mulheres. Empoderamento é o termo advindo da expressão 'empowerment' (Leon, 2000) que remete à capacidade das mulheres de terem controle sobre suas próprias vidas, inclusive sobre seus corpos. A pesquisa feminista tem especial preocupação com o lugar do/a investigador/a na relação com os/as participantes e com o impacto da investigação nos/as participantes da pesquisa. $\mathrm{Na}$ investigação feminista, a relação desigual de poder entre o/a investigador/a e o/a investigado/a é trabalhada de forma a que a perspectiva do/a último/a seja validada e reconhecida como fundamental, considerando-se os/as participantes especialistas das suas próprias experiências (Chrisler \& Smith, 2004; Neves \& Nogueira, 2003; Teitelbaum, 1997).

Algumas pesquisadoras (Bruschini, 1992) postulam que as metodologias feministas referem-se menos à adoção de técnicas específicas de coleta de dados que à inclusão dos aspectos de gênero e de poder na construção do conhecimento. Nesta perspectiva, são igualmente válidas quaisquer abordagens de pesquisa, qualitativas ou quantitativas, desde que construídas e analisadas sob uma perspectiva não sexista. Outras posições (Linton, 1997; Teitelbaum, 1997) concebem as abordagens quantitativas e o uso de testes padronizados nas 
investigações como incompatíveis com as propostas feministas. As abordagens qualitativas são classicamente utilizadas na pesquisa feminista (McHugh \& Cosgrove, 2004), entre elas: as narrativas, a pesquisa-ação, a abordagem fenomenológica, os grupos focais, os estudos de caso, as histórias de vida, o método autobiográfico e os grupos de conceptualização (ver Linton, 1997).

\section{AS TERAPIAS FEMINISTAS}

As proposições feministas, sobretudo no que concerne à crítica ao androcentrismo, à negligência das especificidades da experiência feminina e à discriminação das mulheres, foram incorporadas por diversos campos do saber, em especial pelas Ciências Sociais, pela História, Filosofia, Literatura e Psicologia. Com o incremento dos movimentos feministas a partir da segunda geração do feminismo, nos anos 1970, surgem, especialmente nos Estados Unidos, diversos grupos de conscientização de mulheres. Estes grupos, embora não tivessem o objetivo de ser terapêuticos, funcionavam como tais, uma vez que possibilitavam a troca de experiências de mulheres sobre suas histórias de vida e buscavam estimular a autonomia e a emancipação femininas. Contando com a participação de psicólogas, surgem destes grupos as primeiras terapeutas feministas que, oriundas das tradições humanista e psicanalítica, passaram a repensar suas práticas terapêuticas tradicionais, configurando, então, o campo das terapias e psicologias feministas. A Psicologia Feminista pode ser definida como um espaço estratégico entre o feminismo e a psicologia que critica as concepções tradicionais da psicologia positivista tradicional. Assim, enquanto as terapias tradicionais pretendem-se apolíticas, as terapias feministas assumem um compromisso marcadamente político com a mudança; enquanto as terapias tradicionais recorrem a construtos intrapsíquicos para compreender o sofrimento psíquico, as terapias feministas focalizam os fatores contextuais, em especial as desigualdades e a opressão, como origem das dificuldades individuais e familiares; enquanto as terapias tradicionais buscam 0 ajustamento, a normatização e normalização dos indivíduos e das famílias a papéis tradicionalmente prescritos, as terapias feministas problematizam esses papéis e normas; enquanto as terapias tradicionais estabelecem relações de poder-saber marcadamente desiguais com os/as cliente(s), as terapias feministas validam os saberes individuais e as experiências singulares dos indivíduos e das famílias, valorizando as diversidades e reduzindo o mais possível as diferenças de poder-saber envolvidas na relação terapêutica (Neves \& Nogueira, 2003). Dentre as terapias feministas, destacam-se as terapias feministas da família (Goldner, 1985, 1988; Goodrich e cols., 1990; Hare-Mustin, 1987; Perelberg, 1994; Ravazzola, 1997, 1999; Urry, 1994). As terapias feministas da família buscam o desvelamento e a denúncia dos mecanismos e processos que mantêm o gênero feminino em posições de subordinação; opõem-se à normatização patriarcal das relações familiares; substituem o primado dos construtos intrapsíquicos pelos fatores contextuais na compreensão dos processos de vitimização e de opressão do gênero feminino; ao invés de centrar sua atuação na redução da sintomatologia decorrente dos processos de vitimização decorrentes de experiências reiteradas de desqualificação e violência, a intervenção terapêutica feminista busca validar a experiência feminina, auxiliando as mulheres na identificação de suas capacidades e de suas competências. Orientandoas na busca dos recursos comunitários e legais disponíveis acerca de seus direitos, as terapias feministas comprometem-se com o resgate das competências femininas dentro da perspectiva do empoderamento das mulheres (Leon, 2000), ajudandoas a esboçar estratégias de resistência diante das discriminações e violências sofridas (ver Narvaz, 2005; Neves \& Nogueira, 2003; Rampage \& Avis, 1998).

\section{CONSIDERAÇÕES FINAIS}

Apesar dos estereótipos e preconceitos que circundam a expressão "feminista" (Jones, 1994), provavelmente em função da estreita relação entre teoria e política feminista, a despeito das resistências institucionais, o feminismo invadiu as ciências e adentrou a academia, a pesquisa e a clínica. No entanto, as produções feministas ainda têm um estatuto científico marginal, o que é evidenciado pela dificuldade de sua institucionalização nas universidades e pela publicação ainda circunscrita a poucas revistas científicas especializadas no tema, tais como a Revista Estudos Feministas, da Universidade Federal de Santa Catarina, e a Cadernos Pagu, da Universidade de Campinas (Adelman, 2003; Costa, 1994; Malheiros, 2003). Nos demais periódicos indexados, há pouca produção relativa aos estudos de gênero e, menos ainda, sobre estudos e metodologias feministas. Ainda assim, como diz Malheiros (2003), existe a militância na academia e também se estuda e se pesquisa na militância. 
Consoante com as abordagens feministas, que advogam a ligação do fazer acadêmico com as práticas e lutas sociais (Coimbra, 2004; Fonseca, 1997; Harding,1986; Neves \& Nogueira, 2003, 2005), este texto buscou demonstrar que o feminismo, tanto quanto um movimento político, é também um corpo de conhecimento filosófico-epistemológico, cujas contribuições têm sido negligenciadas, ocultadas e desvalorizadas pelos jogos androcêntricos de saberpoder que perpassam as relações institucionais. É possível e necessário que articulemos pesquisa, clínica e política a fim de seguirmos produzindo saberes e práticas comprometidos e implicados, para o que as metodologias feministas têm, em muito, a contribuir.

\section{REFERÊNCIAS}

Adelman, M. (2003). Dar margens ao centro: refletindo sobre a teoria feminista e a sociologia acadêmica. Estudos Feministas, $11(1), 284-288$.

Aguiar, N. (1997). Perspectivas feministas e conceito de patriarcado na sociologia clássica e no pensamento sociopolítico brasileiro. Em N. Aguiar (Org.), Gênero e ciências humanas: desafio às ciências desde a perspectiva das mulheres (pp.161-191). Rio de Janeiro: Rosa dos Tempos.

Benz, J. N. \& Newman, J. (1998). Research methodology: Qualitative-quantitative. Illinois: University.

Bombassaro, L. C. (1995). Ciência e mudança conceitual. Porto Alegre: EDIPUCRS.

Bruschini, C. (1992). O uso de abordagens quantitativas em pesquisas sobre relações de gênero. Em A. Costa \& C. Bruschini (Orgs.), Uma questão de gênero (pp. 289-309). Rio de Janeiro: Rosa dos Tempos

Burck, C. \& Daniel, G. (1994). Feminismo e terapia estratégica: contradição ou complementação? Em R. J. Perelberg \& A C. Miller (Orgs.), Os sexos e o poder nas famílias (pp. 94-115). Rio de Janeiro: Imago.

Butler, J. (2003). Problemas de gênero: feminismo e subversão da identidade. Rio de Janeiro: Civilização Brasileira.

Castro, M. \& Lavinas, L. (1992). Do feminino ao gênero: a construção de um objeto. Em A. Costa \& C. Bruschini (Orgs.), Uma questão de gênero (pp. 216-251). Rio de Janeiro: Rosa dos Tempos.

Chalmers, A. (1993). O que é a ciência afinal? São Paulo: Brasiliense.

Chrisler, J. C. \& Smith, C. A. (2004). Feminism and psychology. In M. A. Paludi (Org.), Praeger guide to the psychology of gender (pp. 271-292). Westport: Praeger.

Coimbra, C. M. (2004). Gênero, militância, tortura. Em M. Strey, M. Azambuja \& F. Jaeger (Orgs.), Violência, gênero $e$ políticas públicas. (Coleção Gênero e Contemporaneidade, V. II, pp. 45-62). Porto Alegre: EDIPUCRS.

Colling, A. (2004). A construção histórica do feminino e do masculino. Em M. N. Strey, S. T. L. Cabeda \& D. R. Prehn (Orgs.), Gênero e cultura: questões contemporâneas (Coleção Gênero e Contemporaneidade, Vol. I, pp. 13-38), Porto Alegre: EDIPUCRS.
Costa, A. (1994). Os estudos da mulher no Brasil ou a estratégia da corda bamba. Estudos Feministas, (Número Especial), 401409.

Costa, C. L. (2002). O sujeito no feminismo: revisitando os debates. Cadernos Pagu, 19, 59-90.

Costa, C. L. \& Schmidt, S. P. (2004). Feminismo como poética/política. Em C. L. Costa \& S. P. Schmidt (Orgs.), Poéticas e políticas feministas (pp. 9-18). Florianópolis: Mulheres.

Dias, M. O. L. S. (1992). Teoria e métodos dos estudos feministas: perspectiva histórica e hermenêutica do cotidiano. Em A. Costa \& C. Bruschini (Orgs.), Uma questão de gênero (pp. 3953). Rio de Janeiro: Rosa dos Tempos.

Eichler, M. (1988). Nonsexist research methods: A Practical guide. Winchester: Allen \& Unwin.

Fonseca, T. M. G. (1997). Psicologia e relações de gênero: o gênero da ciência psicológica. Em A. V. Zanella, M. J. Siqueira, L. A. Lulhier \& S. I. Molon (Orgs.), Psicologia e práticas sociais (pp. 317-321). Porto Alegre: ABRAPSO.

Fraisse, G. (1995). Entre igualdade e liberdade. Estudos Feministas, 3, 164-171.

Gergen, K. J. (1985). The social constructionist movement in modern psychology. American Psychologist, 40, 266-275.

Goldner, V. (1985). Warning: Family therapy may be hazardous to your health. The Family Therapy Networker, 9 (6), 18-23.

Goldner, V. (1988). The treatment of violence and victimization in intimate relationships. Family Process, 37, 263-286.

Goodrich, T. J., Rampage, C., Ellman, B. \& Halstead, K. (1990). Terapia feminista da família. Porto Alegre: Artes Médicas.

Guba, E. G. \& Lincoln, Y. S. (1994). Competing paradigms in qualitative research. In N. K. Denzin \& Y. S. Lincoln (Eds.), Handbook of qualitative research (pp. 105-117). Thousand Oaks: Sage.

Habermas, J. (1982). Conocimiento y interés. Madrid: Taurus.

Harding, S. (1986). The science question in feminism. Ithaca: Cornell University.

Harding, S. (1987). Feminism and methodology. Indiana: Indiana University.

Harding, S. (1991). Whose science? Whose knowledge? New York: Cornell University.

Harding, S. (1993). A instabilidade das categorias analíticas na teoria feminista. Estudos Feministas 1(1), 7-31.

Hare-Mustin, R. T. (1987). The problem of gender in family therapy theory. Family Process, 26, 15-27.

Jaggar, A. M. (1997). Amor e conhecimento: a emoção na epistemologia feminista. Em A. M. Jaggar \& S. R. Bordo (Orgs.), Gênero, corpo, conhecimento (pp. 157-185). Rio de Janeiro: Rosa dos Tempos.

Jones, E. (1994). Feminismo e terapia de família: os casamentos complicados podem dar certo? Em R. J. Perelberg \& A C. Miller (Orgs.), Os sexos e o poder nas famílias (pp. 75-93). Rio de Janeiro: Imago.

Keller, E. F. (1985). Reflections on gender and science. New Haven: Yale University. 
Keller, E. F. (1996). O paradoxo da subjetividade científica. Em D. Schnitman (Org.), Novos paradigmas, cultura e subjetividade (pp. 93-111). Porto Alegre: Artes Médicas.

Leon, M. (2000). Empoderamiento: Relaciones de las mujeres con el poder. Estudos Feministas, 8, 191-207.

Linton, R. (1997). Rumo a um método feminista de pesquisa. Em A. M. Jaggar \& S. R. Bordo (Orgs.), Gênero, corpo, conhecimento (pp. 293-314). Rio de Janeiro: Rosa dos Tempos.

Louro, G. L. (1995). Gênero, história e educação: construção e reconstrução. Educação e Realidade, 20(2), 101-132.

Louro, G. L. (1999, 3. ed.). Gênero, sexualidade e educação: uma perspectiva pós-estruturalista. Petrópolis: Vozes.

Machado, L. Z. (1992). Feminismo, academia e interdisciplinaridade. Em A. Costa \& C. Bruschini (Orgs.), Uma questão de gênero (pp. 24-38). Rio de Janeiro: Rosa dos Tempos.

Machado, L. Z. (2000, julho). Perspectivas em confronto: relações de gênero ou patriarcado contemporâneo? Simpósio Relações de Gênero ou Patriarcado Contemporâneo. 52 $2^{\mathrm{a}}$ Reunião Brasileira para o Progresso da Ciência: Sociedade Brasileira de Sociologia, Brasília.

Malheiros, S. (2003). Publicando nas ONGs feministas: entre a academia e a militância. Estudos Feministas, 11(1), 271-283.

Mariano, S. A. (2005). O sujeito do feminismo e o pósestruturalismo. Estudos Feministas, 13(3), 483-505.

McConaghy, J. S. \& Cottone, R. R. (1988). The systemic view of violence: An ethical perspective. Family Process, 37, 51-63.

McHugh, M. C. \& Cosgrove, L. (2004). Feminist research methods: Studying women and gender. In M. A. Paludi (Ed.), Praeger guide to the psychology of gender (pp. 155-182). Westport: Praeger.

Millet, K. (1970). Sexual politics. New York: Doubleday \& Company.

Narvaz, M. (2005). Submissão e resistência: explodindo o discurso patriarcal da dominação feminina. Dissertação de Mestrado Não-Publicada, Programa de Pós-Graduação em Psicologia do Desenvolvimento, Universidade Federal do Rio Grande do Sul, Porto Alegre.

Negrão, T. (2002). Feminismo no plural. Em M. Tiburi, M. M. Menezes \& E. Eggert (Orgs.), As mulheres e a filosofia (pp. 271-280). São Leopoldo: UNISINOS.

Neves, S. \& Nogueira, C. (2003). A psicologia feminista e a violência contra as mulheres na intimidade: a (re)construção dos espaços terapêuticos. Psicologia e Sociedade, 15(2), 4364.

Neves, S. \& Nogueira, C. (2005). Metodologias feministas: a reflexividade a serviço da investigação nas Ciências Sociais. Psicologia Reflexão e Crítica, 18 (3), 408-412.

Nogueira, C. (2001). Feminismo e discurso do gênero na psicologia social. Psicologia e Sociedade, 13(1), 107-128.

Pateman, C. (1993). O contrato sexual. Rio: Paz e Terra.

Pereira, V. L. (2004). Gênero: dilemas de um conceito. Em M. N. Strey, S. T. L. Cabeda \& D. R. Prehn (Orgs.), Gênero e cultura: questões contemporâneas (Coleção Gênero e Contemporaneidade, Vol. I, pp. 173- 198), Porto Alegre: Edipucrs.
Perelberg, R. J. (1994). Igualdade, assimetria e diversidade: sobre as conceitualizações dos sexos. Em R. J. Perelberg \& A C. Miller (Orgs.), Os sexos e o poder nas famílias (pp. 47-67). Rio de Janeiro: Imago.

Prá, J. R. (1997). O feminismo como teoria e como prática. Em M. Strey (Org.), Mulher: Estudos de gênero (pp. 39- 57). São Leopoldo: UNISINOS.

Rampage, C. \& Avis, J. M. (1998). Identidade sexual, feminismo e terapia familiar. Em M. Elkaim (Org.), Panorama das terapias familiares (pp. 189-251). São Paulo: Summus.

Ravazzola, M. C. (1997). Violencia familiar: el abuso relacional como un ataque a los derechos humanos. Sistemas Familiares, 23, 29-42.

Ravazzola, M. C. (1999). Historias infames: los maltratos en las relaciones. Buenos Aires: Paidós.

Saffioti, H. (1979). A mulher na sociedade de classes: mitos $e$ realidade. Rio de Janeiro: Rocco.

Saffioti, H. (1988). Movimentos sociais: a face feminina. Em N. V. Carvalho (Org.), A condição feminina (pp. 143-178). São Paulo: Vértice.

Saffioti, H. (2001). Contribuições feministas para o estudo da violência de gênero. Cadernos Pagu, 16, 115-136.

Schmidt, S. P. (2004). Como e por que somos feministas. Estudos Feministas, 12(Número Especial.), 17-22.

Scott, J. W. (1986). Gender: A useful category of historical analysis. The American Historical Review, 91(5), 1053-1101.

Scott, J. W. (2005). O enigma da igualdade. Estudos Feministas, 13(1), 11-30.

Slife, B. D. \& Williams, R. N. (1995). What's behind the research. London: Sage.

Teitelbaum, P. (1997). A teoria feminista e os testes padronizados. Em A. M. Jaggar \& S. R. Bordo (Orgs.), Gênero, corpo, conhecimento (pp. 333-345). Rio de Janeiro: Rosa dos Tempos.

Toledo, C. (2003, 2.ed.). Mulheres: o gênero nos une, a classe nos divide. Série Marxismo e opressão. São Paulo: José Luís e Rosa Sundermann.

Toscano, M. \& Goldenberg, M. (1992). A revolução das mulheres: um balanço do feminismo no Brasil. Rio de Janeiro: Revan.

Urry, A. (1994). A luta por uma prática feminista na terapia de família: Premissas. Em R. J. Perelberg \& A C. Miller (Orgs.), Os sexos e o poder nas famílias (pp.116-130). Rio de Janeiro: Imago.

Wilkinson, S. (1986). Feminist social psychology. Milton Keynes: Open University.

Wilkinson, S. (1998). Feminist research: Focus groups in feminist research: Power, interaction and the co-construction of meaning. Women's Studies International Forum, 21, 111-125.

Recebido em 27/05/2005 Aceito em 02/06/2006

Endereço para correspondência: Martha Giudice Narvaz. Av. Wenceslau Escobar, 1086, ap. 919, CEP 91900-000, Porto Alegre-RS, Brasil. E-mail: phoenx@terra.com.br 